\title{
Enteric dispersion of Serratiopeptidase with Eudragit L100 and Formulation of Controlled Release Tablets of Serratiopeptidase
}

\author{
A Prameela Rani and Annapurna Uppala* \\ University College of Pharmaceutical Sciences, Acharya Nagarjuna University, \\ Nagarjuna Nagar - 522510, India
}

\begin{abstract}
Serratiopeptidase is an anti inflammatory enzyme commonly used in the treatment of various inflammatory disorders. It is found to have no GI related side effects unlike NSAIDs and can be safely used for chronic conditions. Formulations of controlled release tablets can decrease the frequency of administration and thereby improve the patient compliance. As Serratiopeptidase is acid-liable, it is made into enteric dispersion with the polymer viz. Eudragit L 100 by solvent evaporation technique. The polymer is used in various proportions and the optimum solid dispersion was selected based on the drug release study for enteric products. The controlled release tablets of the Serratiopeptidase solid dispersion were prepared with the polymers viz. ethyl cellulose, hydroxypropylmethylcellulose and methylcellulose in various proportions. Drug release study was conducted for 6 hours in $\mathrm{pH} 6.8$ phosphate buffer. The formulation containing ethyl cellulose in $125 \mathrm{mg}$ quantity showed drug release in controlled manner upto 6 hours.

Key words: Enteric dispersion, Serratiopeptidase, Eudragit L100, Controlled Release Tablets.
\end{abstract}

\section{Introduction ${ }^{1-6}$}

Serratiopeptidase is an anti-inflammatory enzyme derived from the non-pathogenic enterobacteria Serratia marcescences strain E15. It is a systemic enzyme which is highly specific for its substrate without eliciting any side effects. It is devoid of unpleasant actions created by inhibition of the COX-1 enzymes unlike NSAIDs. Moreover it has an antioedemic and fibrinolytic action which makes it useful in sciatic pain, sinusitis, pneumonia, skin rash, tonsillitis, atherosclerotic pain and post child birth complications. Various marketed products of Serratiopeptidase belong to the class of immediate release and need intake of drug for thrice a day. In the present work an attempt was made to formulate controlled release tablets of Serratiopeptidase in order to decrease the frequency of administration.

Initially enteric dispersion of Serratiopeptidase with Eudragit L 100 was prepared by solvent evaporation technique. The selected solvent can dissolve the enteric polymer whereas serratiopeptidse is insoluble in it. This facilitates fine dispersion between the drug and the polymer. The enteric dispersion was 
optimized based on the assay and the drug release study for enteric products. Then controlled release formulations were designed to contain the enteric dispersion of Serratiopeptidase and drug release retarding polymers namely ethyl cellulose, hydroxypropylmethylcellulose and methyl cellulose in different concentrations.

\section{Material and Methods ${ }^{1-6}$}

Serratiopeptidase (J.C. Biotech Pvt Ltd., ongole), Eudragit L 100, Ethyl cellulose, Hydroxypropyl methylcellulose and Methyl cellulose are the ingredients used in the present work. All other materials used were of analytical grade.

\subsection{Preparation of enteric dispersion}

Drug and enteric polymer - Eudragit L 100 were taken in different proportions viz, 1:01, 1:0.2, 1:0.3, 1:0.4 and 1:0.5. Initially polymer was dissolved in ethanol taken in a round bottomed flask and then specific quantity of Serratiopeptidase was added to it and mixed well. This mixture was subjected to evaporation at 41 degree centigrade using rotary evaporator until a dry powder was obtained. The solid dispersion was collected from the round bottomed flask, pulverised and stored under appropriate conditions in a dessicator.

\subsection{Evaluation of enteric dispersion}

\subsubsection{Assay}

Each solid dispersion was tested for the drug content. Definite quantity of solid dispersion equivalent to $10 \mathrm{mg}$ of solid dispersion was weighed and dissolved in $10 \mathrm{ml}$ of methanol. Dilute the solution suitably with pH 6.8 phosphate buffer and record the absorbance using UV spectrophotometer.

\subsubsection{Dissolution study}

$100 \mathrm{mg}$ of solid dispersion of different ratios was compressed into tablets. Dissolution study was conducted for 2 hours in $0.1 \mathrm{~N} \mathrm{HCl}$ and then in $\mathrm{pH} 6.8$ phosphate buffer for one hour. $5 \mathrm{ml}$ samples were withdrawn at regular intervals of 30 minutes and samples are analyzed spectrophotometrically.

\subsection{Preparation of Controlled release tablets}

Formulations consisting of solid dispersion equivalent to 30mg of Serratiopeptidase were prepared with release retarding polymers namely ethyl cellulose, hydroxypropylmethylcellulose, methyl cellulose in different concentrations. Wet granulation followed by lubrication and compression of tablets was done using rotary tablet punching machine.

Table 1 Formulations of controlled release tablets

\begin{tabular}{|l|l|l|l|l|l|l|l|l|l|l|}
\hline S.No. & \multicolumn{1}{|c|}{ Ingredients } & $\begin{array}{c}\text { SEC } \\
\mathbf{1}\end{array}$ & $\begin{array}{c}\text { SEC } \\
\mathbf{2}\end{array}$ & $\begin{array}{c}\text { SEC } \\
\mathbf{3}\end{array}$ & $\begin{array}{c}\text { SHP } \\
\mathbf{1}\end{array}$ & $\begin{array}{c}\text { SHP } \\
\mathbf{2}\end{array}$ & $\begin{array}{c}\text { SHP } \\
\mathbf{3}\end{array}$ & $\begin{array}{c}\text { SMC } \\
\mathbf{1}\end{array}$ & $\begin{array}{c}\text { SMC } \\
\mathbf{2}\end{array}$ & $\begin{array}{c}\text { SMC } \\
\mathbf{3}\end{array}$ \\
\hline 1 & Enteric dispersion & 43 & 43 & 43 & 43 & 43 & 43 & 43 & 43 & 43 \\
\hline 2 & Ethyl cellulose & 75 & 100 & 125 & - & - & - & - & - & - \\
\hline 3 & $\begin{array}{l}\text { Hydroxypropylmethylcellu } \\
\text { lose }\end{array}$ & - & - & - & 75 & 100 & 125 & - & - & - \\
\hline 4 & Methyl cellulose & - & - & - & - & - & - & 75 & 100 & 125 \\
\hline 5 & Microcrystalline cellulose & 80 & 55 & 30 & 80 & 55 & 30 & 80 & 55 & 30 \\
\hline 6 & Magnesium stearate & 3 & 3 & 3 & 3 & 3 & 3 & 3 & 3 & 3 \\
\hline 7 & Total & 200 & 200 & 200 & 200 & 200 & 200 & 200 & 200 & 200 \\
\hline
\end{tabular}




\subsection{Evaluation of Controlled release tablets ${ }^{1-6}$}

The prepared tablets were evaluated for weight uniformity, hardness, friability and drug content.

\subsubsection{Dissolution study}

Dissolution study was conducted for 2 hours in $0.1 \mathrm{~N} \mathrm{HCl}$ and then in $\mathrm{pH} 6.8$ phosphate buffer for 6 hours. $5 \mathrm{ml}$ samples were withdrawn at regular intervals of 30 minutes and samples are analyzed spectrophotometrically.

\section{Results and Discussion ${ }^{1-6}$}

\subsection{Evaluation of enteric dispersion}

\subsubsection{Assay}

Table 1 Formulations of controlled release tablets

\begin{tabular}{|l|l|l|l|}
\hline S.No & $\begin{array}{l}\text { Drug:Polymer } \\
\text { ratio }\end{array}$ & $\begin{array}{l}\text { Weight of drug } \\
\text { present }(\mathbf{m g})\end{array}$ & $\begin{array}{l}\text { Percentage of } \\
\text { drug content }\end{array}$ \\
\hline 1 & $1: 0.1$ & 5.64 & 88.4 \\
\hline 2 & $1: 0.2$ & 9.88 & 98.8 \\
\hline 3 & $1: 0.3$ & 5.68 & 86.8 \\
\hline 4 & $1: 0.4$ & 10.15 & 101.5 \\
\hline 5 & $1: 0.5$ & 4.32 & 93.2 \\
\hline
\end{tabular}

Out of the different enteric dispersions, the dispersion containing drug: polymer in 1:0.4 ratio was found to have more drug content while the dispersion with 1:0.3 has the least drug content.

\subsubsection{Drug release data of enteric dispersion}

Table 3: Drug release data of enteric dispersion

\begin{tabular}{|l|l|l|l|l|l|l|}
\hline S.No & $\begin{array}{l}\text { Time of sampling } \\
\text { (hours) }\end{array}$ & \multicolumn{5}{|l|}{ Percentage of drug dissolved } \\
\hline $\mathbf{0 . 1 N}$ Hcl & & $\mathbf{1 : 0 . 1}$ & $\mathbf{1 : 0 . 2}$ & $\mathbf{1 : 0 . 3}$ & $\mathbf{1 : 0 . 4}$ & $\mathbf{1 : 0 . 5}$ \\
\hline $\mathbf{1}$ & $\mathbf{0 . 5}$ & 13.35 & 15.43 & 16.34 & 15.31 & 15.36 \\
\hline $\mathbf{2}$ & $\mathbf{1 . 0}$ & 20.16 & 23.13 & 26.89 & 17.63 & 18.29 \\
\hline $\mathbf{3}$ & $\mathbf{1 . 5}$ & 28.34 & 30.16 & 33.26 & 18.34 & 20.73 \\
\hline $\mathbf{4}$ & $\mathbf{2 . 0}$ & 32.54 & 34.32 & 39.39 & 19.25 & 25.64 \\
\hline pH 6.8 buffer & $\mathbf{0 . 5}$ & & & & & \\
\hline $\mathbf{1}$ & $\mathbf{1 . 0}$ & 16.45 & 14.31 & 12.16 & 5.23 & 10.45 \\
\hline $\mathbf{2}$ & 23.56 & 20.45 & 19.34 & 16.34 & 15.16 \\
\hline
\end{tabular}

With the increase in polymer proportion, it was found that the drug release from enteric dispersion into $0.1 \mathrm{~N} \mathrm{HCl}$ was found to be decreased which can be attributed to the increase in entrapped quantity of drug in the polymer matrix and thereby decreased drug release from the enteric dispersion. at the end of 2 hours enteric dispersion with the drug-polymer ratio of 1:0.4 showed a drug release of 
$19.25 \%$ while other dispersions had a drug release of more than $25 \%$ within 2 hours. Based on this it was selected as the optimum enteric dispersion for formulation into controlled release tablets.

\subsection{Evaluation of controlled release tablets}

All the tablets were found to have percentage weight variation, hardness, $\%$ friability and percentage drug content within the pharmacoepial limits.

\subsubsection{Drug release study of controlled release tablets}

Table 4 : Drug release study data of controlled release tablets

\begin{tabular}{|l|l|l|l|l|l|l|l|}
\hline S.No & $\begin{array}{l}\text { Time of } \\
\text { sampling } \\
\text { (hrs) }\end{array}$ & \multicolumn{6}{l|l|}{ Percentage of drug released (avg+-S.D.) (n=3) } \\
\hline & & SEC $_{1}$ & SEC $_{2}$ & SEC $_{3}$ & SHP $_{1}$ & SHP $_{2}$ & SHP $_{3}$ \\
\hline 1 & 0.5 & $6.86 \pm 0.68$ & $5.34 \pm 0.88$ & $8.23 \pm 0.56$ & $6.45 \pm 0.81$ & $4.98 \pm 1.12$ & $3.98 \pm 0.73$ \\
\hline 2 & 1.0 & $12.22 \pm 0.94$ & $10.34 \pm 0.76$ & $14.36 \pm 0.98$ & $14.56 \pm 0.59$ & $10.88 \pm 0.97$ & $8.42 \pm 0.58$ \\
\hline 3 & 1.5 & $21.67 \pm 1.23$ & $16.56 \pm 0.13$ & $22.34 \pm 0.76$ & $21.56 \pm 0.78$ & $16.62 \pm 0.99$ & $14.56 \pm 0.896$ \\
\hline 4 & 2.0 & $30.89 \pm 1.35$ & $23.45 \pm 0.7$ & $31.23 \pm 0.67$ & $28.32 \pm 0.59$ & $21.14 \pm 0.54$ & $18.34 \pm 1.18$ \\
\hline 5 & 2.5 & $32.98 \pm 0.53$ & $29.23 \pm 0.56$ & $40.12 \pm 0.98$ & $36.69 \pm 0.88$ & $26.34 \pm 0.68$ & $22.65 \pm 0.58$ \\
\hline 6 & 3.0 & $44.22 \pm 0.87$ & $35.48 \pm 0.66$ & $46.25 \pm 1.16$ & $43.54 \pm 0.78$ & $31.89 \pm 0.87$ & $46.87 \pm 0.98$ \\
\hline 8 & 4.0 & $66.11 \pm 0.89$ & $61.78 \pm 0.58$ & $59.76 \pm 0.54$ & $63.78 \pm 0.58$ & $49.78 \pm 0.78$ & $51.78 \pm 0.24$ \\
\hline 9 & 5.0 & $77.72 \pm 0.57$ & $71.92 \pm 0.73$ & $67.49 \pm 1.15$ & $76.79 \pm 0.66$ & $58.8 \pm 0.63$ & $69.89 \pm 0.58$ \\
\hline 10 & 6.0 & $85.5 \pm 0.89$ & $82.82 \pm 0.89$ & $72.31 \pm 0.32$ & $87.21 \pm 0.40$ & $76.88 \pm 0.87$ & $75.88 \pm 0.51$ \\
\hline
\end{tabular}

\begin{tabular}{|c|c|c|c|c|}
\hline \multirow[t]{2}{*}{ S.No } & \multirow[t]{2}{*}{$\begin{array}{l}\text { Time of } \\
\text { sampling (hrs) }\end{array}$} & \multicolumn{3}{|c|}{ Percentage of drug released } \\
\hline & & $\mathrm{SMC}_{1}$ & SMC2 & $\mathrm{SMC}_{3}$ \\
\hline 1 & 0.5 & $6.23 \pm 0.64$ & $4.32 \pm 1.12$ & $3.11 \pm 1.04$ \\
\hline 2 & 1.0 & $11.76 \pm 0.85$ & $7.54 \pm 0.68$ & $5.92 \pm 0.56$ \\
\hline 3 & 1.5 & $16.78 \pm 0.53$ & $11.53 \pm 0.56$ & $8.34 \pm 1.18$ \\
\hline 4 & 2.0 & $24.46 \pm 0.98$ & $16.67 \pm 0.85$ & $11.34 \pm 0.98$ \\
\hline 5 & 2.5 & $28.87 \pm 0.67$ & $20.45 \pm 0.51$ & $15.56 \pm 0.54$ \\
\hline 6 & 3.0 & $36.76 \pm 1.07$ & $24.35 \pm 0.64$ & $20.45 \pm 0.6$ \\
\hline 7 & 3.5 & $47.98 \pm 0.85$ & $28.67 \pm 0.98$ & $26.66 \pm 1.12$ \\
\hline 8 & 4.0 & $53.66 \pm 0.96$ & $36.78 \pm 0.51$ & $32.36 \pm 0.58$ \\
\hline 9 & 5.0 & $64.66 \pm 0.98$ & $44.45 \pm 0.66$ & $36.68 \pm 0.54$ \\
\hline 10 & 6.0 & $82.34 \pm 0.56$ & $76.66 \pm 0.53$ & $75.55 \pm 0.89$ \\
\hline
\end{tabular}

Among the nine formulations prepared, SEC3 was found to show drug release of $72.31 \%$ in 6 hours while the other formulations had drug release greater than that formulation which may be attributed to the hydrophobic nature of ethylcellulose unlike the two other polymers used. 


\section{Fig 1: Zero order graph of dissolution}

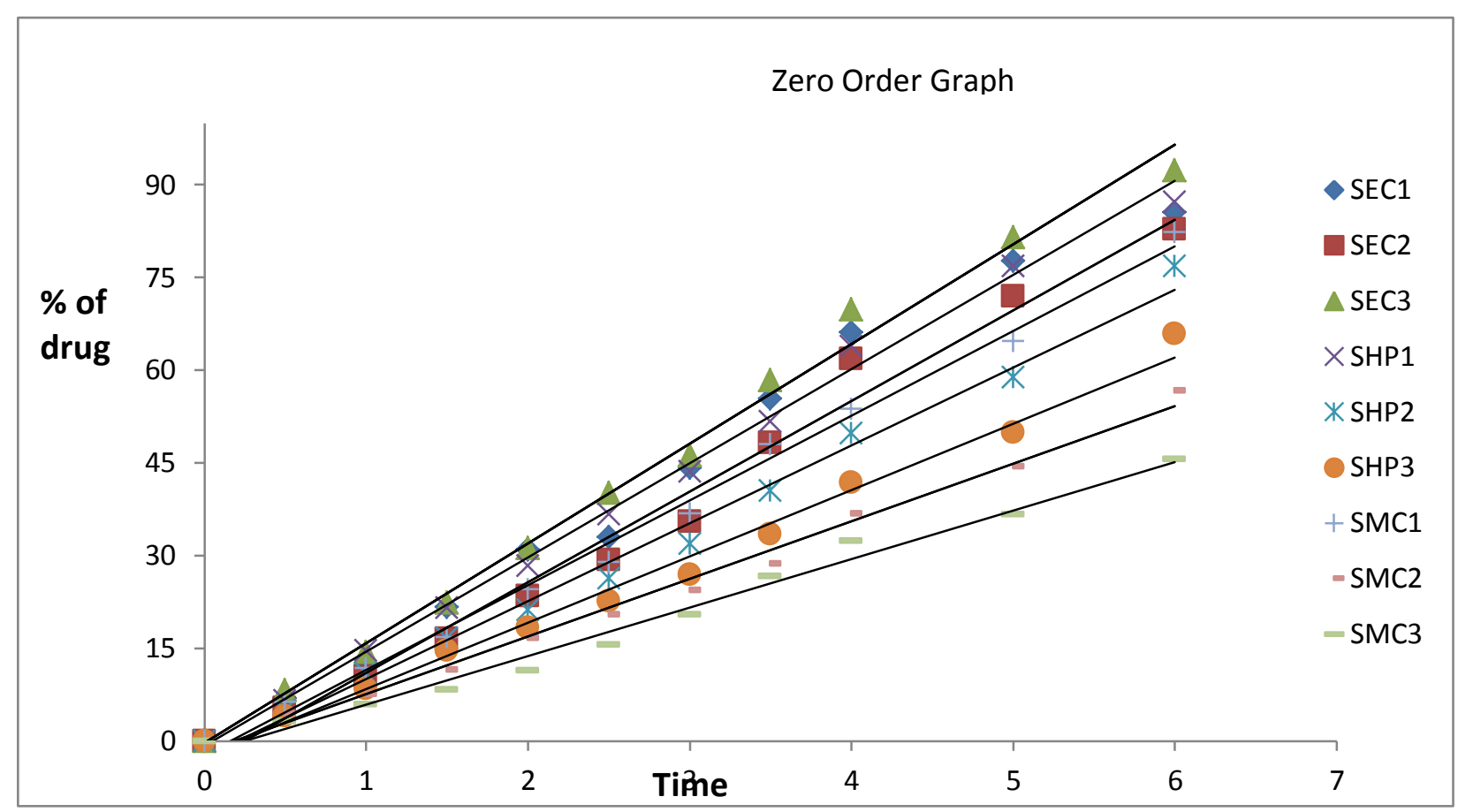

Table 5: Kinetics of dissolution of controlled release tablets

\begin{tabular}{|l|l|l|l|l|l|}
\hline S.No & $\begin{array}{l}\text { Formulation } \\
\text { Code }\end{array}$ & \multicolumn{2}{l|}{ Regression Coefficient value } & \multirow{2}{*}{ Peppas 'n' value } \\
\cline { 1 - 2 } & & Zero order & First order & Higuchi & \\
\hline 1 & $\mathrm{SEC}_{1}$ & 0.985 & 0.742 & 0.884 & 1.195 \\
\hline 2 & $\mathrm{SEC}_{2}$ & 0.985 & 0.850 & 0.871 & 1.141 \\
\hline 3 & $\mathrm{SEC}_{3}$ & 0.995 & 0.863 & 0.876 & 0.987 \\
\hline 4 & $\mathrm{SHP}_{1}$ & 0.989 & 0.784 & 0.885 & 1.147 \\
\hline 5 & $\mathrm{SHP}_{2}$ & 0.980 & 0.802 & 0.885 & 1.030 \\
\hline 6 & $\mathrm{SHP}_{3}$ & 0.984 & 0.800 & 0.885 & 0.949 \\
\hline 7 & $\mathrm{SMC} 1$ & 0.988 & 0.634 & 0.873 & 1.084 \\
\hline 8 & $\mathrm{SMC} 2$ & 0.987 & 0.813 & 0.879 & 0.916 \\
\hline 9 & $\mathrm{SMC} 3$ & 0.990 & 0.730 & 0.873 & 0.795 \\
\hline
\end{tabular}

The regression coefficients of zero order were found to be nearer to 1 . So the drug release from the tablets follows zero order kinetics. The value for Higuchi's mechanism were found to be far away from 1 and the Peppa's $n$ values are in the range of 0.795-1.195 indicating the drug release following anamolous diffusion mechanism but not Higuchi's mechanism.

\section{Conclusion:}

Based on the results it can be concluded that the prepared enteric dispersion with the drug:polymer ratio of 1:0.4 was found to have enteric character and the tablets prepared with that dispersion using ethyl cellulose in $62.5 \% \mathrm{w} / \mathrm{w}$ exhibited drug release in controlled manner upto 6 hours as confirmed by regression coefficient values for zero order and peppas mechanism. 


\section{Acknowledgements:}

The authors acknowledge the material support of J.C.Biotech Pvt.Ltd.Ongole, Andhra Pradesh and that of the Acharya Nagarjuna University, India.

\section{References:}

1. Limce Thampi, Swamivelmanickam M, and Kuppuswamy S, Preparation, Evaluation And Optimization Of Etodolac Solid Dispersion For Delayed Drug Release, RJPBCS 2017, 8 (4).

2. Grandhi Srikar et al, Development Of Extended Release Matrix Tablets Of Felodipine Through Solid Dispersions For Better Drug Release Profile By A 32 Factorial Design, Indian Journal Of Pharmaceutical Education And Research, 2016, 50 (2), 889-895.

3. Ann Newman; Amorphous Dispersion Screening In Pharmaceutical Amorphous Solid Dispersions, John Wiley \& Sons, 2015, Pg-91,100.

4. Peng Hou et al, Preparation And Evaluation Of Solid Dispersions Of A New Anti-Tumour Compound Based On Early -Stage Preparation Discovery Concept, AAPS Pharmscitech 2013 Jun; 14(2); 629-638.

5. Ramond C.Rose, Paul J Shesky, Sian C Owen, Hand Book Of Pharmaceutical Excipients, Sixth Edition, Pharmaceutical Press, London, 2012, Pg-278,346,462,553.

6. Rawat M Et Al., Formulation Optimization Of Double Emulsification Method For Preparation Of Enzyme-Loaded Eudragit S100 Microspheres, Journal of Microencapsulation, 2009 Jun, 26(4), 30614doi:10.1080/02652040802319767. 